\title{
Prevalence of mitral prolapse by two dimensional echocardiography in healthy young women
}

\author{
L SAMUEL WANN, J ROBERT GROVE, TIMOTHY R HESS, LINDA GLISCH, MICHAEL J \\ PTACIN, C VINCENT HUGHES, CHARLES M GROSS
}

From Medical College of Wisconsin, the Wood VA Medical Center, and the Milwaukee County Medical Complex, Milwaukee, Wisconsin, USA

SUMMARY In order to establish the relative prevalence of mitral valve prolapse as diagnosed by two dimensional echocardiography, we studied 100 presumably healthy young women with two dimen- $\dot{\omega}$ sional echocardiography and $\mathbf{M}$-mode echocardiography, history, physical examination, electrocar- $\rightarrow$ diography, and phonocardiography. Two dimensional echocardiograms were obtained from para- $\frac{\rho}{工}$ sternal, apical, and subcostal acoustic windows. Mitral valve prolapse was defined as extension of $\rightarrow \vec{D}$ leaflet tissue cephalad to the plane of the mitral annulus into the left atrium; note was also made of $\frac{D}{0}$ any valvular thickening, redundancy, or excessive annular motion. One subject had a midsystolic $=$ click and late systolic murmur with evidence of mitral prolapse on both $M$-mode and two dimen- $\infty$ sional echocardiography. One subject had a midsystolic click with mitral prolapse demonstrated by $\omega$ two dimensional but not on $M$-mode echocardiography. One subject had a thick mitral valve on echocardiography but no click or murmur. Four subjects had midsystolic clicks without echocardiographic abnormalities. Mild artefactual pansystolic posterior bowing of the mitral valve on the $\bar{\partial}$ M-mode echocardiogram could be produced in 20 subjects by incorrect transducer position. We $\frac{\otimes}{\varnothing}$ conclude that the prevalence of mitral valve prolapse by two dimensional echocardiography is $\cong$ relatively low in presumably healthy young women. Use of two dimensional echocardiography may $\stackrel{0}{0}$ avoid overdiagnosis of mitral prolapse and identify a smaller group of individuals with true anatomical abnormalities of the mitral valve.

Over the past 20 years, numerous reports have documented the association of mitral valve prolapse with the auscultatory findings of non-ejection midsystolic clicks and late systolic murmurs. ${ }^{1-5}$ Subsequently, numerous reports have appeared ${ }^{6-10}$ suggesting the usefulness of M-mode echocardiography in making a diagnosis of mitral valve prolapse even in the absence of the accepted auscultatory findings. This has resulted in a dramatic increase in the alleged incidence of mitral valve prolapse, up to $21 \%$ of presumably healthy young women in one report. ${ }^{11}$ Thus, there is considerable controversy regarding the clinical significance of an M-mode echocardiographic diagnosis of mitral prolapse to the point where some clinicians are reluctant to base a diagnosis of mitral prolapse solely on the $\mathrm{M}$-mode echocardiogram. ${ }^{12}$

Supported in part by grants from the Veterans Administration, the NIHNHLBI, and the American Heart Association of Wisconsin, Inc.

Accepted for publication 11 January 1983
More recently, two dimensional echocardiography has been used to detect the abnormal pathology rep- $\sigma$ resenting the prolapsed mitral valve. ${ }^{13} 14$ Because of its unique ability to provide information on intracar- $\bigcirc$ diac structure, two dimensional echocardiography may be a more specific and sensitive means for diag-은 nosing mitral prolapse and has been proposed as the $>$ "gold standard" for such diagnosis. ${ }^{15}$ We therefore used two dimensional echocardiography to assess the $\bar{N}$ prevalence of mitral prolapse in presumably healthy young women, a group generally thought to be more $\tilde{N}$ frequently affected by this syndrome.

\section{Subjects and methods}

Studies were performed on 100 female volunteers $\stackrel{\mathbb{D}}{\rightarrow}$ aged 18 years to 35 years (mean 25 years) who consi- $T$ dered themselves to be in good health and who denied ${ }^{\circ}$ a prior diagnosis of cardiac disease. Most subjects $\stackrel{D}{\Omega}$ were nurses, medical students, and other hospital per- $\mathbb{D}$ sonnel. The subjects were not paid. 
After giving informed consent, each subject filled out a medical questionnaire which was later reviewed with an examining cardiologist. Specific note was made of drug use, symptoms possibly related to heart disease, and family history of cardiovascular abnormality. A thorough cardiovascular physical examination was performed independently by two cardiologists in a quiet room. Auscultation of the heart was performed in the supine, sitting, and standing positions and after squatting and during the strain phase of a Valsalva manoeuvre. A search was made for thoracic bony abnormalities including pectus excavatum and absence of normal thoracic kyphosis and for stigmata of Marfan's syndrome. Abnormalities detected by either examiner were recorded as positive.

A 12 lead electrocardiogram was recorded. Phonocardiograms were obtained in the supine position during suspended respiration before and after inhalation of amyl nitrite. Microphones were placed at the mid left sternal border and apex and filtered to display high (200 to $500 \mathrm{~Hz}$ ), medium (100 to 200 $\mathrm{Hz}$ ), and low (50 to $100 \mathrm{~Hz}$ ) frequencies. Tracings were made at $50 \mathrm{~mm} / \mathrm{s}$ with a simultaneous electrocardiogram and carotid pulse tracing using an Electronics for Medicine VR-12 recorder. Each record was examined independently by two cardiologists who had no knowledge of other findings. Clicks, murmurs, and other abnormalities reported by either examiner were regarded as positive.

M-mode echocardiograms were performed using an Electronics for Medicine Echo IV ultrasonoscope and a $2.25 \mathrm{MHz}$ transducer focused at $5 \mathrm{~cm}$. Subjects were studied in the 30 degree left lateral position. Recordings were made with the transducer at the left sternal border from as many intercostal spaces as possible. Note was made of the intercostal space from which the mitral valve could be recorded with the transducer remaining most nearly perpendicular to the chest wall. Numerous sweeps from the aortic valve and left atrium to the mitral valve and left ventricle were obtained. Each M-mode echocardiogram was reviewed by two independent observers who had no knowledge of other findings. Particular attention was directed toward detection of late systolic step-like posterior displacement of the mitral valve or pansystolic posterior bowing of greater than $2 \mathrm{~mm}$ posterior to a line connecting the $C$ and $D$ points of the mitral valve recording. Pansystolic or late systolic posterior motion greater than $2 \mathrm{~mm}$ recorded with the transducer perpendicular to the chest wall was regarded as true prolapse while posterior motion recorded from a non-perpendicular position was regarded as artefactual prolapse.

Two dimensional echocardiograms were obtained with either a V3000 or V3400 Varian Associates ultrasonoscope and a $2.25 \mathrm{MHz}$ wide angle phased array transducer. Standard views were obtained from the parasternal, apical, and subcostal acoustic windows and recorded on videotape for subsequent review. Records were analysed independently by two observers in real time, slow motion, and stop frame formats. Neither observer had knowledge of the M-mode echocardiographic findings or other clinical features of the cases. A specific search was made for evidence of mitral tissue extending through the plane of the mitral annulus into the left atrium during systole on the parasternal long axis, apical four and two chamber, and subcostal four chamber views using the methods of Gilbert et al. ${ }^{14}$ and Morganroth et al ${ }^{15} \mathrm{~A}$ qualitative judgement was also made regarding the presence of any valvular thickening, redundancy, or excessive motion of the leaflets or valve ring. ${ }^{14} \mathrm{~A}$ finding of mitral prolapse by either observer on either the M-mode or two dimensional examination was regarded as positive evidence for mitral valve prolapse. Special note was made of any potential false positive findings.

\section{Results}

TWO DIMENSIONAL ECHOCARDIOGRAPHY

Abnormalities were identified in the two dimensional echocardiograms obtained from three subjects. In one subject, both the anterior and posterior mitral leaflets sagged into the left atrium during systole (Fig. 1). The mitral leaflets were both thin and pliable and showed no evidence of significant thickening or redundancy. There were no signs of left atrial enlargement or left ventricular volume overload. Motion of the mitral annulus was normal. The M-mode echocardiogram from this patient (Fig. 2) showed typical late systolic posterior displacement. Physical examination and phonocardiography disclosed a midsystolic click and late systolic murmur. The electrocardiogram was normal. There were no skeletal abnormalities or stigmata of connective tissue disease. The subject denied cardiac symptoms but had fainted several years previously.

A second subject had only a mid to late systolic click on auscultation and phonocardiography. Physical examination was otherwise normal. The electrocardiogram and M-mode echocardiogram were normal. The two dimensional echocardiogram showed prolapse of a small part of both the anterior and posterior mitral leaflets above the plane of the mitral annulus without valvular thickening or redundancy. Motion of the mitral annulus did not appear to be excessive. The subject denied cardiac symptoms. A family member reportedly had a heart murmur.

A third subject had mild thickening of the anterior mitral leaflet on both the two dimensional and 


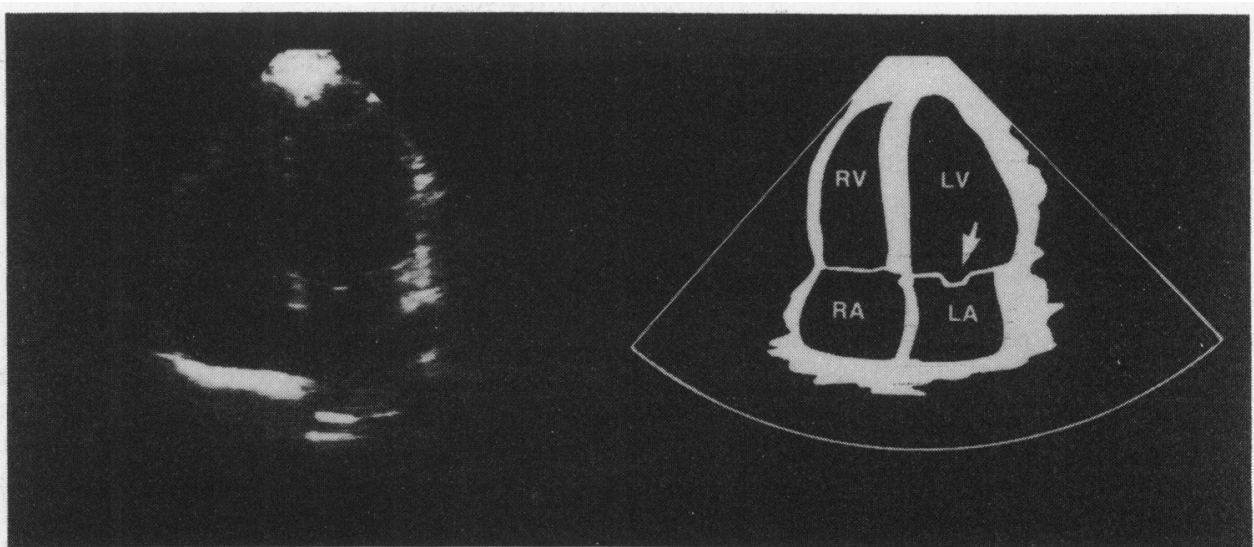

Fig. 1 Apical four chamber view of the two dimensional echocardiogram of a subject with mitral valve prolapse. $R V$, right ventricle; $L V$, left ventricle; $L A$, left atrium; $R A$, right atrium. The mitral leaflets can be seen curling into the left atrium in this systolic frame (arrow).

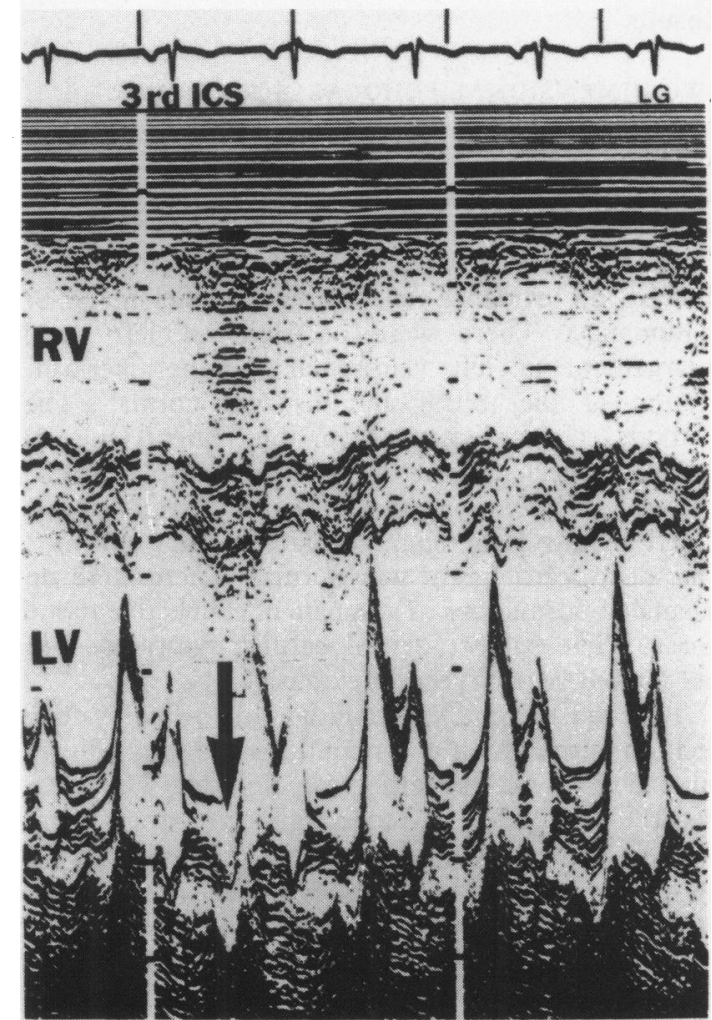

Fig. $2 M$-mode echocardiogram of the same subject as illustrated in Fig 1 . The arrow is directed to an area of typical late systolic posterior bowing of the mitral leaflets which represents mitral valve prolapse.
M-mode echocardiograms. There was no evidence of mitral valve prolapse. The physical examination, phonocardiogram, and electrocardiogram were normal. The subject denied cardiac symptoms and had no history of rheumatic fever.

\section{M-MODE ECHOCARDIOGRAPHY}

$M$-mode echocardiography showed the characteristic late systolic step-like posterior displacement characteristic of mitral valve prolapse in the one previously mentioned subject. In the remaining subjects a wide variety of mitral valve motion patterns was recorded during systole, but none satisfied the criteria for true mitral valve prolapse. Multiple patterns were seen in most patients, the pattern varying with transducer location and angulation. In 20 subjects it was possible to obtain records showing slight pansystolic posterior bowing (greater than $2 \mathrm{~mm}$ ) of the mitral valve by positioning the transducer high on the chest wall and angling towards the mitral valve in a non-perpendicular fashion (Fig. 3). None of these 20 subjects had abnormalities on physical examination, phonocardiography, electrocardiography, or two dimensional echocardiography. Two subjects complained of easy fatiguability and seven had a family history of cardiovascular disease.

\section{PHYSICAL EXAMINATION AND}

PHONOCARDIOGRAPHY

In addition to the one previously mentioned subject with a midsystolic click and late systolic murmur and one with an isolated midsystolic click and mitral prolapse by two dimensional echocardiography, four subjects were identified who had isolated midsystolic clicks without M-mode or two dimensional echocar- 


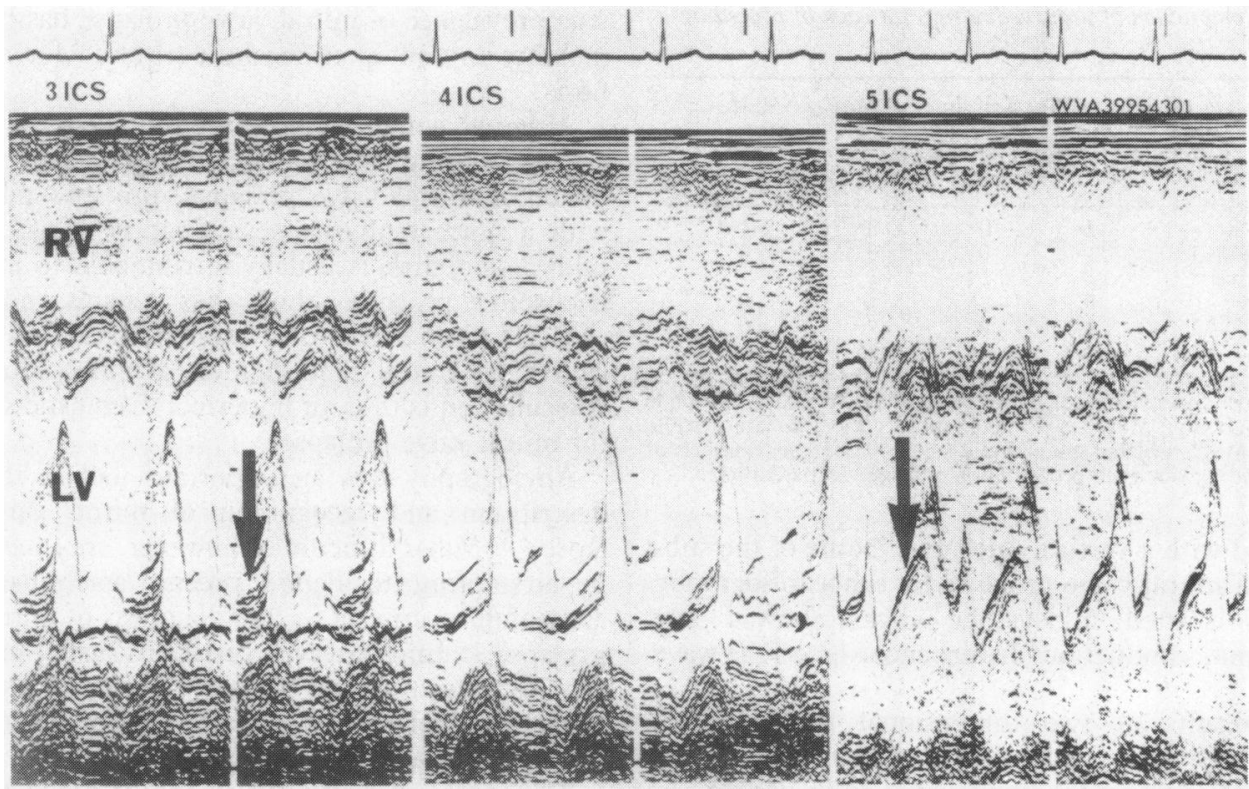

Fig. 3 M-mode echocardiogram of a normal subject who had no evidence of mitral prolapse on two dimensional echocardiography, phonocardiography, or physical examination. The panel at the far left was obtained at the third intercostal space (3 ICS) with the transducer angled in a caudad fashion. The arrow is directed to an area of posterior motion of the mitral valve which represents artefactual mitral prolapse. The middle panel was obtained from the fourth intercostal space (4 ICS) with the transducer perpendicular to the chest wall. The mitral valve courses in a normal anterior direction during systole. In the right hand panel, the transducer was in the fifth intercostal space and angled in a cranial direction. The arrow is directed to an area of exaggerated systolic anterior motion of the mitral valve.

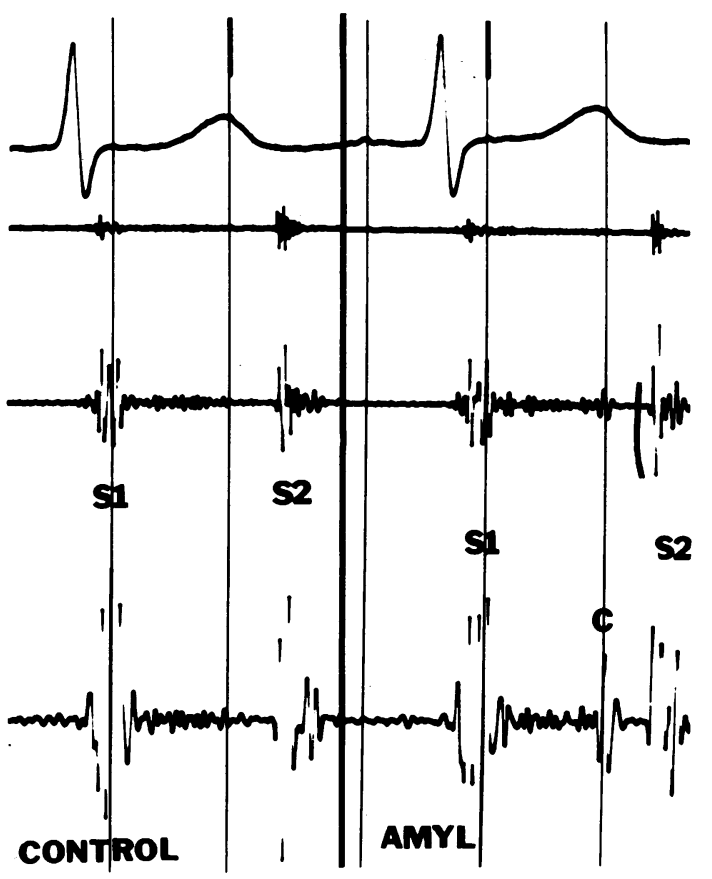

diographic abnormalities. All had normal electrocardiograms and denied cardiac symptoms. In two subjects the midsystolic clicks were only identified on phonocardiography after amyl nitrite inhalation (Fig. 4). In the remaining two subjects the midsystolic clicks were observed without provocation on both phonocardiography and physical examination. None of the four subjects had any other evidence of cardiovascular abnormalities.

\section{ELECTROCARDIOGRAPHY}

All subjects were in sinus rhythm. Mean PR interval was $0.14 \mathrm{~s}$, ranging from 0.11 to $0.20 \mathrm{~s}$. Two subjects had premature atrial contractions and one had an intraventricular conduction defect. Mean QRS axis was +57 degrees, range 0 to +100 degrees. Two subjects had $\mathrm{T}$ wave inversion in leads II, III, and aVF

Fig. 4 Phonocardiogram recorded at the mid left sternal border in a patient with no evidence of mitral valve prolapse on either $M$-mode or two dimensional echocardiography. Low, medium, and high frequency filters were used. Note that on the control recording, no clicks or murmurs are present. After amyl nitrite administration a prominent late systolic click $(C)$ is seen. S1 furst heart sound : $S 2$ second heart sound. 
Table Comparison of positive findings for each of procedures employed

\begin{tabular}{|c|c|c|c|c|c|}
\hline & $\begin{array}{l}+2 D E \\
(2)\end{array}$ & $\stackrel{+M-\text { mode }}{(1)}$ & $\begin{array}{l}\text { False } \\
\text { positive } \\
\text { M-mode } \\
(20)\end{array}$ & $\begin{array}{l}M S C-L S M \\
(1)\end{array}$ & $\underset{(5)}{M S C}$ \\
\hline$+2 \mathrm{DE}$ & - & 1 & 0 & 1 & 1 \\
\hline $\begin{array}{l}+M \text {-mode } \\
\text { False positive }\end{array}$ & 1 & - & 0 & 1 & 0 \\
\hline M-mode & 0 & 0 & - & 0 & 0 \\
\hline MSC-LSM & 1 & 1 & 0 & - & 0 \\
\hline MSC & 1 & 0 & 0 & 0 & - \\
\hline
\end{tabular}

2DE, two dimensional echocardiography; M-mode, M-mode echocardiography; MSC-LSM, midsystolic click and late systolic murmur; MSC, isolated midsystolic click. The total number of positive findings for each procedure is indicated in parentheses.

associated with a vertical QRS axis. None of the subjects with mitral valve prolapse by echocardiography or with isolated midsystolic clicks showed any arrhythmia, conduction disturbance, or ST-T wave changes.

The results of two dimensional and M-mode echocardiography, physical examination, and phonocardiography are summarised in the Table.

\section{Discussion}

Using two dimensional echocardiography as our diagnostic standard, we found only two cases of mitral valve prolapse in a series of 100 presumably healthy young women. One of these cases could not be diagnosed by $\mathrm{M}$-mode echocardiography. One additional subject had slight thickening of the mitral leaflets, a finding of unknown significance. The prevalence of mitral valve prolapse as diagnosed by two dimensional echocardiography in our study population thus appears to be much less than that determined by previous studies which used phonocardiography, auscultation, and M-mode echocardiography as diagnostic standards. ${ }^{2} 111617$

We also observed four additional subjects who had isolated midsystolic clicks; the click appeared in two subjects only after amyi nitrite inhalation. In the absence of other evidence indicating abnormality of the mitral valve, the site of origin of these clicks and their clinical significance are unknown. ${ }^{11}$

For many reasons, the true prevalence of mitral valve prolapse has been difficult to establish. Prevalence may depend in part on the age, sex, associated disease processes, and other factors governing the selection of the population studied. Since mitral valve prolapse is usually a benign condition, surgical observations are not representative of the general population. A specific search for postmortem signs of mitral prolapse has not been made in any large necropsy series of patients dying from non-cardiac causes. But perhaps the greatest impediment to establishing the true prevalence of mitral valve prolapse has been the inability to define an absolute criterion for its diag - . nosis.

Although a midsystolic non-ejection click and a late systolic murmur are widely accepted as specific evi-등 dence of mitral valve prolapse, prolapse may existe with a normal physical examination. ${ }^{18}$ An isolated midsystolic click is usually attributable to mitral or tricuspid prolapse but has many additionafs causes $^{19-22}$ and mid to late systolic murmurs may be $\overrightarrow{0}$ caused by mitral regurgitation of other aetiologies. Auscultation is thus an imperfect diagnostic standarow for mitral valve prolapse.

Angiography was an important tool in the early description and recognition of mitral valve proce lapse. ${ }^{423}$ Major difficulties, however, are encountere $f_{\omega}^{\sharp}$ in attempting to define precise and quantifiable angiographic criteria for the diagnosis of mitral valveo prolapse. ${ }^{24}$ Interobserver variability using angiogra $=$ phy to detect mitral valve prolapse is extremely high, ${ }^{25}$ and many question the use of this invasive procedure as a diagnostic standard. ${ }^{26}$

The initial descriptions of the M-mode echocar $\infty$ diographic features of mitral valve prolapse focuse of on late systolic posterior displacement of the mitraf leaflets. ${ }^{6-8}$ Though the $M$-mode pattern of late sys tolic posterior displacement appears to be a feature reasonably specific for mitral valve prolapse, manyö patients with well documented prolapse do not show this classical pattern. ${ }^{9}$ Pansystolic posterior bowing of the mitral leaflets may also be seen in mitral valve prolapse ${ }^{910}$ but is a much less specific finding. ${ }^{27}$

The technical aspects of the $M$-mode echocardio graphic examination are extremely important to con sider in the prevention of false positive and false nega $\frac{\mathbb{D}}{\mathrm{W}}$ tive diagnoses. If the ultrasound transducer is place of high on the chest wall and angled caudad to record the mitral valve, pansystolic posterior bowing of the inis tial leaflets can be produced in normal subjects. ${ }^{28} 29$ In the present study, some pansystolic posterior bowing was produced artefactually in 20 of 100 normal sub jects by placing the transducer in an abnormally high intercostal space.

Positioning of the M-mode transducer in an unusu ally low intercostal space may obscure features of mitral prolapse. ${ }^{11}$ Even classical late systolic posteriof displacement of the mitral valve can be partiall masked when the transducer is not perpendicular to the valve leaflets. It is likely that transducer position ing was responsible for the one negative $M$-mod echocardiogram in this study obtained from a subject with mitral prolapse on two dimensional echocardiog raphy.

Findings of mitral valve prolapse by $\mathrm{M}$-mode echocardiography and auscultation are frequentlo disparate. In one series, $41 \%$ of subjects with none 
ejection clicks or late systolic murmurs had no evidence of prolapse by $M$-mode echocardiography. ${ }^{11}$ Conversely, $33 \%$ of echoes in this series which showed mitral prolapse were not associated with ausculatory abnormalities. Comparisons of $\mathrm{M}$-mode echocardiography and cineangiography have yielded similarly confusing results..$^{3031}$

Two dimensional echocardiography has clarified many of the problems encountered by M-mode echocardiography. ${ }^{13}$ The vector of abnormal mitral leaflet motion in prolapse appears to be in a superior as well as posterior direction. This superiorly directed abnormal motion may not be detected by the anteroposteriorly directed M-mode beam. In fact, superior motion of the leaflet may cause the $M$-mode beam to pass through an entirely different part of the valve during systole than during diastole. The spatial resolution of two dimensional echocardiography allows ready appreciation of the artefacts seen on M-mode echocardiography caused by high or low transducer position relative to the mitral valve.

Systolic superior movement of one or both mitral leaflets above the level of the mitral ring and posterior displacement of leaflet coaptation have been described as the primary abnormalities seen on the two dimensional echocardiogram in mitral prolapse. ${ }^{14}$ Additional features may include a systolic curling motion of the mitral ring. Two dimensional echocardiography vividly displays areas of thickening and redundancy in severely affected valves and can detect torn chordae tendineae and flail leaflets. ${ }^{32} 33$ Two dimensional echocardiography appears to be more sensitive in detecting mitral valve prolapse than either angiography or M-mode echocardiography. ${ }^{14}$

Two dimensional echocardiographic views obtained from an apical acoustic window appear to be particularly useful in detecting mitral valve prolapse. ${ }^{34}$ The plane of the mitral valve ring is especially easy to define in the apical views, allowing ready detection of any mitral tissue abnormally extending into the left atrium. Two dimensional echocardiography may also allow detection of tricuspid and aortic valve prolapse. ${ }^{15}$

The use of two dimensional echocardiography in the current study showed a lesser prevalence of mitral prolapse than previous studies using other modes of diagnosis. Mitral valve prolapse was still a frequent finding, occurring in $2 \%$ of the population studied. Bias in selection of the study population may have had an effect on these results. For example, most of the subjects in this study were hospital personnel who may have had a more sophisticated knowledge of cardiac disease and could have undergone more thorough diagnostic screening procedures before volunteering for this study. Subjects with mitral valve prolapse may thus have already been diagnosed and therefore not volunteered for this study. Alternatively, many of the subjects included in this study admitted to previous knowledge that they had a heart murmur, not a reason for exclusion unless a physician had told the subject that the murmur represented a definite heart abnormality, and therefore the primary incentive for volunteering for this study may have been a free cardiac consultation. Others may have failed to volunteer because of fear that an abnormality would be found.

We conclude that two dimensional echocardiography identifies a small but significant number of subjects in an otherwise healthy population of young women who have anatomical abnormalities of the mitral valve indicative of mitral valve prolapse. The prevalence of mitral valve prolapse diagnosed by two dimensional echocardiography in this study is much less than that previously reported using other techniques. Two dimensional echocardiography appears to provide a superior description of the pathological anatomy of mitral prolapse and allows a direct specific diagnosis. The numerous advantages of two dimensional echocardiography make it as close to a "gold standard" for the diagnosis of mitral valve prolapse as is currently available. Hopefully, reliance on two dimensional echocardiography to detect the anatomical and structural abnormalities of mitral valve prolapse will avoid overdiagnosis and identification of large segments of the normal healthy population as having heart disease. Further study will be required to relate two dimensional echocardiographic features of mitral valve prolapse to symptoms, prognosis, and the efficacy of intervention. The genesis and significance of isolated midsystolic clicks without echocardiographic abnormalities remain uncertain. It is possible that longitudinal studies of such subjects will show evolution of typical mitral valve prolapse. Alternatively, isolated midsystolic clicks, particularly those occurring only after provocative manoeuvres, may not originate in the mitral valve at all and may be of no clinical significance.

\section{References}

1 Reid JVO. Mid-systolic clicks. S Afr Med F 1963; 35: 353-5.

2 Barlow J, Pocock W, Marchand P, Denny M. The significance of late systolic murmurs. Am Heart $\mathcal{F}$ 1963; 66: 443-52.

3 Barlow JB, Bosman CK, Pocock WA, Marchand P. Late systólic murmurs and non-ejection (mid-late) systolic clicks: an analysis of 90 patients. Br Heart $\mathcal{F}$ 1968; 30: 203-18.

4 Hancock EW, Cohn $\mathrm{K}$. The syndrome associated with midsystolic click and late systolic murmur. Am $\mathcal{F}$ Med 1966; 41: 183-96.

5 Criley JM, Lewis KB, Humphries JO, Ross RS. Prolapse of the mitral valve: clinical and cine-angiocardio- 
graphic findings. Br Heart $\mathcal{F}$ 1966; 28: 488-96.

6 Shah PM, Gramiak R. Echocardiographic recognition of mitral valve prolapse [Abstract]. Circulation 1970; 42 (suppl III): 45.

7 Dillon JC, Haine CL, Chang S, Feigenbaum H. Use of echocardiography in patients with prolapsed mitral valve. Circulation 1971; 43: 503-7.

8 Kerber RE, Isaeff DM, Hancock EW. Echocardiographic pattern in patients with the syndrome of systolic click and late systolic murmur. $N$ Engl F Med 1971; 284: 691-3.

9 DeMaria AN, King JF, Bogren HG, Lies JE, Mason DT. The variable spectrum of echocardiographic manifestations of the mitral valve prolapse syndrome. Circulation 1974; 50: 33-41.

10 Popp RL, Brown OR, Silverman JF, Harrison DC. Echocardiographic abnormalities in the mitral valve prolapse syndrome. Circulation 1974; 49: 428-33.

11 Markiewicz W, Stoner J, London E, Hunt SA, Popp RL. Mitral valve prolapse in one hundred presumably healthy young females. Circulation 1976; 53: 464-73.

12 Cheitlin MD, Byrd RC. The click-murmur syndrome-a clinical problem in diagnosis and treatment. $\mathcal{F} A M A$ 1981; 245: 1357-61.

13 Sahn DJ, Allen HD, Goldberg SJ, Friedman WF. Mitral valve prolapse in children-a problem defined by realtime cross-sectional echocardiography. Circulation 1976; 53: 651-7.

14 Gilbert BW, Schatz RA, VonRamm OT, Behar VS, Kisslo JA. Mitral valve prolapse. Two-dimensional echocardiographic and angiographic correlation. Circulation 1976; 54: 716-23.

15 Morganroth J, Jones RH, Chen CC, Naito M. Twodimensional echocardiography in mitral, aortic, and tricuspid valve prolapse. Am $\mathcal{f}$ Cardiol 1980; 46: 1164-77.

16 Procacci PM, Savran SV, Schreiter SL, Bryson AL. Prevalence of clinical mitral-valve prolapse in 1169 young women. $N$ Engl $\mathcal{F}$ Med 1976; 294: 1086-8.

17 Darsee JR, Mikolich JR, Nicoloff NB, Lesser LE. Prevalence of mitral valve prolapse in presumably healthy young men. Circulation 1979; 59: 619-22.

18 Jeresaty RM. Mitral valve prolapse. New York: Raven Press, 1979.

19 Sze KC, Shah PM. Pseudoejection sound in hypertrophic subaortic stenosis. Circulation 1976; 54: 504-9.

20 Pieroni DR, Bell BB, Krovetz LJ, Varghese PJ, Rowe RD. Auscultatory recognition of aneurysm of the membranous ventricular septum associated with small ventricular septal defect. Circulation 1971; 44: 733-9.

21 Roelandt J, Willems J, Van der Hauwaert LG, de Geest
H. Clicks and sounds (whoops) in left sided pneumothorax. Dis Chest 1969; 56: 31-6.

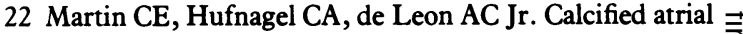
myxoma: diagnostic significance of the "systolic tumor sound" in a case presenting as tricuspid insufficiency. Am Heart f 1969; 78: 245-50.

23 Ranganathan N, Silver MD, Robinson TI, et al. Angiographic-morphologic correlation in patients with severe mitral regurgitation due to prolapse of the posterior mitral valve leaflet. Circulation 1973; 48: 514-9.

24 Farry JP, Simon AL, Ross AM, Cohen LS, Wolfson S. $\vec{\circ}$ Quantitative angiographic assessment of the mitral annulus in the prolapsing mitral leaflet syndrome $[\mathrm{Ab}-$ stract]. Circulation 1975; 51 (suppl II): 12.

25 DeMaria AN, Neumann A, Lee G, Mason DT. Echocardiographic indentification of the mitral valve prolapse syndrome. Am f Med 1977; 62: 819-29.

26 Popp RL, Winkle RA. Mitral-valve prolapse syndrome. FAMA 1976; 236: 867-70.

27 Feigenbaum H. Echocardiography. 3rd ed. Philadelphia: Lea and Febiger, 1981: 259.

28 Markiewicz W, Popp RL. Effect of transducer placement on echocardiographic mitral valve motion. $A m$ Heart $\mathcal{f}$ 1978; 96: 555-6.

29 Markiewicz W, Stoner J, London E, Hunt S, Popp RL. Effect of transducer placement on echocardiographic $\infty$ mitral valve systolic motion. Eur $\mathcal{f}$ Cardiol 1976; 4/3: 359-66.

30 Malcolm AD, Boughner DR, Kostuk WJ, Ahuja SP. Clinical features and investigative findings in the presence of mitral leaflet prolapse. Study of 85 consecutive patients. Br Heart $\mathcal{F}$ 1976; 38: 244-56.

31 Boughner DR. Correlation of echocardiographic and angiographic abnormalities in mitral valve prolapse. In: White DN, ed. Ultrasound in Medicine. vol. 1. New York: Plenum, 1975: 55-62.

32 Mintz GS, Kotler MN, Segal BL, Parry WR. Twodimensional echocardiographic recognition of ruptured chordae tendineae. Circulation 1978; 57: 244-50.

33 Child JS, Skorton DJ, Taylor RD, et al. M-mode and cross-sectional echocardiographic features of flail posterior mitral leaflets. Am $\mathcal{F}$ Cardiol 1979; 44: 1383-90.

34 Morganroth J, Mardelli TJ, Naito M, Chen CC. Apical cross-sectional echocardiography. Standard for the diagnosis of idiopathic mitral valve prolapse syndrome. Chest $\mathrm{O}$ 1981; 79: 23-8.

Requests for reprints to Dr L Samuel Wann, Cardiol- N ogy Section, Wood VA Medical Center, Wood, Wisconsin 53193, USA. 